\title{
A report of Meloidogyne javanica on black pepper (Piper nigrum) in Binh Phuoc Province, Vietnam
}

\author{
Phong Vũ Nguyễn ${ }^{1} \cdot$ Phong Thanh Nguyễn ${ }^{2}$. Oanh Thu Thị Võ ${ }^{2}$ • Đôn Đình Lê ${ }^{1}$
}

Received: 11 August 2019 / Accepted: 7 April 2020 / Published online: 17 April 2020

(C) Australasian Plant Pathology Society Inc. 2020

\begin{abstract}
Root and rhizospheric soil of diseased black pepper plants from Binh Phuoc Province were collected. Based on morphological characteristics and molecular markers, the presence of Meloidogyne javanica was confirmed. In greenhouse conditions, nematode completed the life cycle in 35 days after inoculation on black pepper (Piper nigrum) cv. Vinh Linh. To our knowledge, this is the first report of M. javanica on black pepper in Vietnam.
\end{abstract}

Keywords Morphology $\cdot$ Pathogenicity $\cdot$ Root-knot nematode

Black pepper (Piper nigrum) is a high-value tropical plant in Vietnam. Root-knot nematodes (Meloidogyne spp.) were recorded on black pepper many years ago in the south of Vietnam (Khương 1983). In 2002, a survey conducted from more than four hundred soil and root samples resulted in thirty-five plant-parasitic nematode taxa belonging to 19 genera and 11 families. It is worth noting that all root-knot nematode populations collected on black pepper plants were identified exclusively as $M$. incognita (Thuy et al. 2012). In recent years, soil-borne diseases and plantparasitic nematodes have caused severe damage in many black pepper growing areas in the Central Highlands (Gia Lai, Dak Nong) and Southeast (Ba Ria - Vung Tau, Đong Nai, and Binh Phuoc). Leaves of diseased vines turn yellowish-green, and the infected leaves gradually fall from the lower to the upper parts of the vine (Fig. 1a). The rhizosphere soil samples and galled roots were collected from slowly declining vines in the Bu Dang and $\mathrm{Bu}$ Dop districts, Binh Phuoc Province (Fig. 1b).

Phong Vũ Nguyễn

nvphong97@gmail.com

1 Department of Biotechnology, Nông Lâm University - Hồ Chí Minh City, Ho Chi Minh City, Vietnam

2 Faculty of Agronomy, Nông Lâm University - Hồ Chí Minh City, Ho Chi Minh City, Vietnam
Females and egg masses were dissected from the galled roots. Second-stage juveniles (J2s) were obtained by placing egg masses in sterile water for 48 to $72 \mathrm{~h}$ at $28{ }^{\circ} \mathrm{C}$ (Nguyễn et al. 2014). Males were obtained according to the method of Snyder et al. (2006). The morphological and morphometric characteristics of females, males, and $\mathrm{J} 2 \mathrm{~s}$ were observed and measured under an optical microscope (Olympus).

The perineal pattern of nematodes $(n=10)$ with the high dorsal arch and double lateral lines were characterised (Fig. 2a). In comparison with the description of Eisenback (1985), this is characteristic of M. javanica. Measurements of J2s $(n=30)$ included body length $=440 \pm 23.1$ (380 to 500) $\mu \mathrm{m}$, greatest body width $=15.5 \pm 1.7(12.5$ to 22.5$)$ $\mu \mathrm{m}, \mathrm{a}=28.8 \pm 3.5(19.6-36.6), \mathrm{c}=8.2 \pm 0.7$ (6.1-9.4), stylet length $=12.5 \pm 0.7$ (10 to 15$) \mu \mathrm{m}$, tail length $=53.9 \pm 3.7$ (47.5 to 65$) \mu \mathrm{m}$, head to median bulb length $=60.3 \pm 3.2$ $(52.5$ to 67.5$) \mu \mathrm{m}$, dorsal esophageal gland orifice $(\mathrm{DGO})=$ $3.8 \pm 0.4(3.0-4.5) \mu \mathrm{m}$. The males were cylindroid and vermiform with a robust stylet, arcuate spicule, and short and rounded tail. Male morphometrics $(n=9)$ include body length $=$ $1152 \pm 103.1$ (985 to 1340$) \mu \mathrm{m}$, greatest body width $=34.6$ \pm 1.9 (25.5 to 37.5$) \mu \mathrm{m}$, stylet length $=19.4 \pm 1.35$ (17.5 to 21.3) $\mu \mathrm{m},(\mathrm{DGO})=4.04 \pm 0.52$ (3.25 to 5.0$) \mu \mathrm{m}$, spicule length $=31.3 \pm 1.13(29.7-32.5) \mu \mathrm{m}$. The overall morphology and morphometrics of these populations of Meloidogyne were similar to the description by Rammah and Hirschmann (1990) on M. javanica. Specimen of perineal pattern was deposited in the collection of the Institute of 
Fig. 1 (a) Symptoms of diseased vines where leaves turned yellowish-green in Bu Dang, Binh Phuoc Province; (b) Black pepper roots infected with rootknot nematode

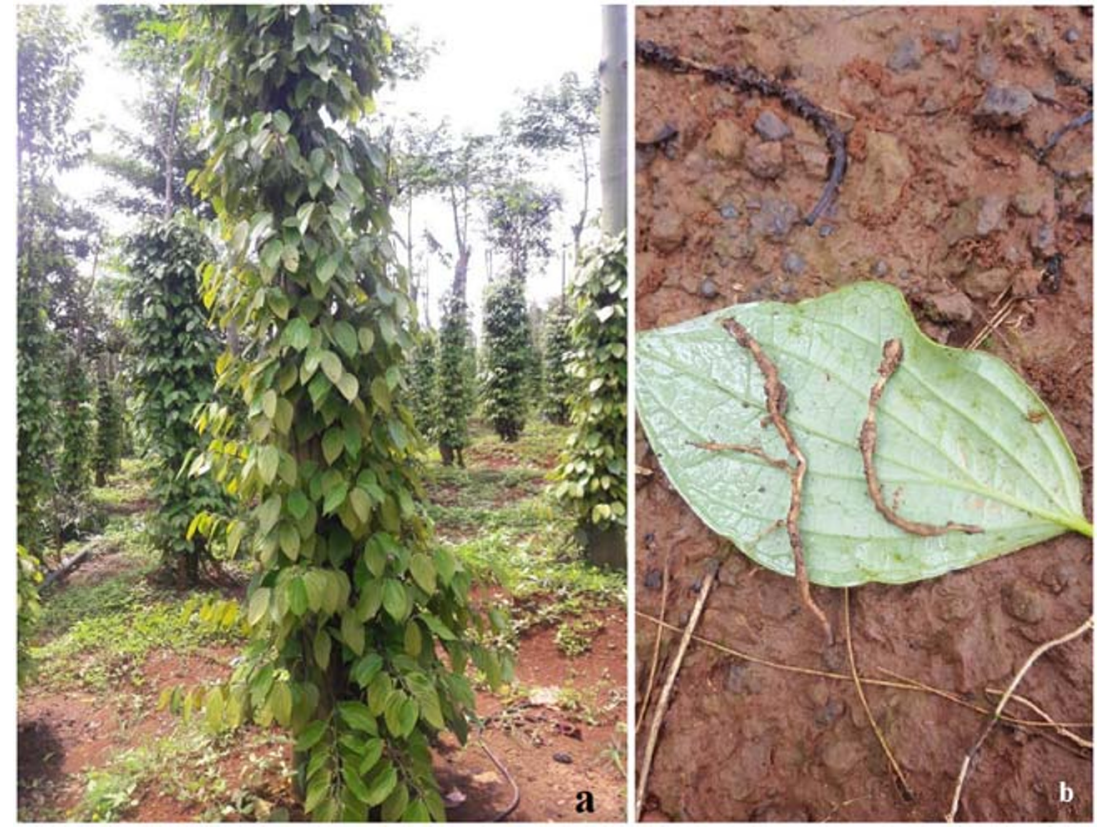

Ecology and Biolognical Resources, Vietnam (Accession Number: IEBR-Nema 6063).

Besides, the molecular identification of specimens was also carried out. Genomic DNA of the female nematode was extracted by using Gene JET Genomic DNA Purification Minikit (Thermo Scientific, USA). The PCR amplicon produced the expected fragment length of 670 bp with Fjav prim- er (5'- GGT GCG CGA TTG AAC TGA GC -3') and Rjav primer (5'- CAG GCC CTT CAG TGG AAC TAT AC- 3`) (Zijlstra et al. 2002), no product with MI-F primer (5'- GTG AGG ATT CAG CTC CCC AG -3') and MI-R primer (5'ACG AGG AAC ATA CTT CTC CGT CC -3') was observed (Meng et al. 2004) (Fig. 2b). The DNA sequence from the $M$. javanica isolate in this study was deposited in GenBank

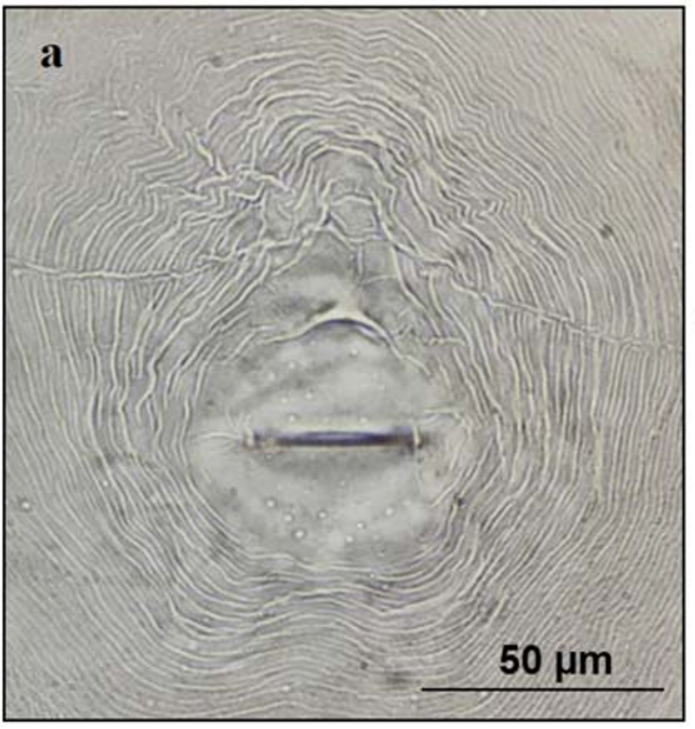

Fig. 2 (a) The specific perineal pattern of Meloidogyne javanica with low to moderately high dorsal arches and having two conspicuous lateral lines; (b) DNA amplification product obtained from two Meloidogyne isolates from Binh Phuoc Province. (M) DNA ladder (HyperLadder

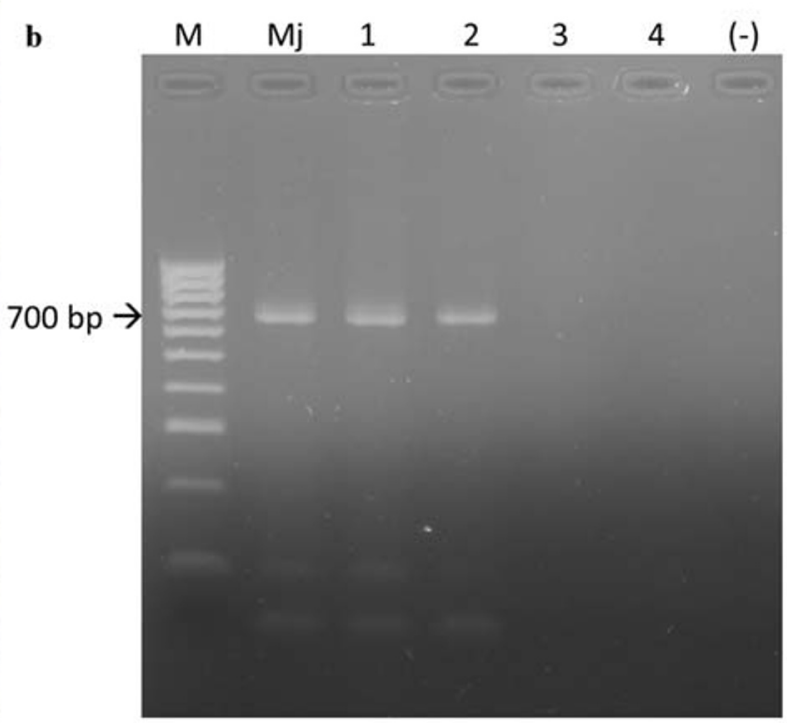

100 bp, Bioline); (1) isolate from Bu Dang; (2) isolate from Bu Dop; (3) isolate from $\mathrm{Bu}$ Dang with Mi-SCAR primers; (4) isolate from $\mathrm{Bu}$ Dop with Mi-SCAR primers; (-) without DNA template 


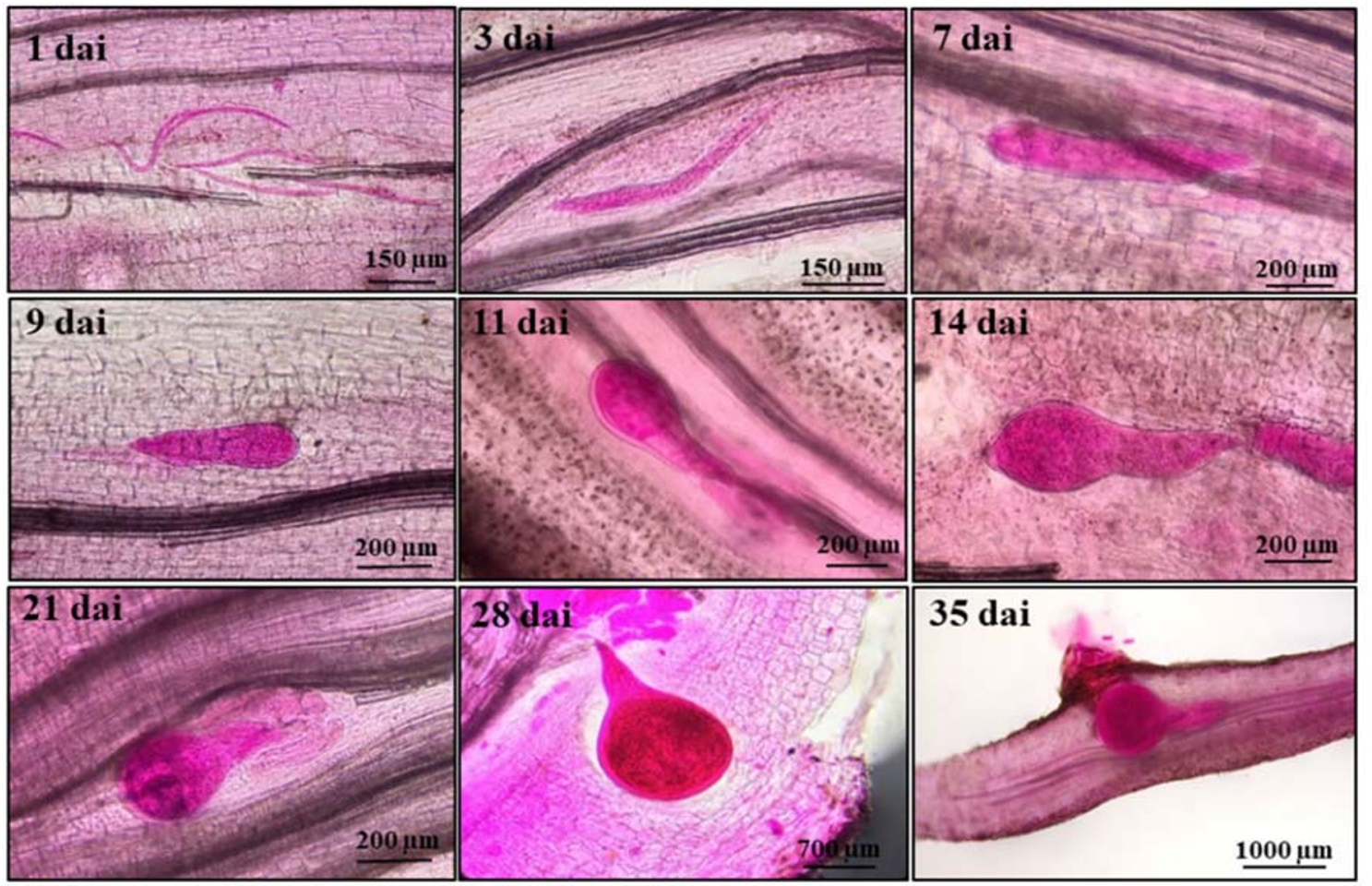

Fig. 3 Life cycle of Meloidogyne javanica in root of back pepper cv. Vinh Linh. (dai) days after inoculation; (1 dai) the juveniles penetrated the root; (3 dai) third-stage (J3); (7 dai and 9 dai) fourth-stage (J4); (11 dai and 14

accession: MN380721. The blast search results of DNA sequence revealed the best match with $98-99 \%$ identity to sequences corresponding to $M$. javanica isolates from China, India, Malaysia, and Thailand.

Fifteen two-month-old black pepper vines (cv. Vinh Linh) were maintained in a greenhouse in $20-\mathrm{cm}$ diameter $\times 16-\mathrm{cm}$ tall pots with sterilized soil. They were inoculated with 2000 freshly hatched J2s. Infected roots were stained by the fuchsin acid method according to Bybd et al. (1983). The juveniles penetrated the root tips $12 \mathrm{~h}$ following inoculation, and they molted to the thirdstage (J3) 3 days after inoculation (dai). The fourth-stage (J4) and the J4 (female) were found at 7 dai and 14 dai, respectively. At 21 dai, females with gelatinous matrices were scored, egg-laying and the emergence of secondstage juveniles were observed at 35 dai (Fig. 3). After 60 dai, the pathogenicity assay showed that the aboveground parts and roots of both inoculated and controlled plants exhibited similar length and weight $(n=15$, data not shown). The nematode reproduction factor (final population divided by initial population) was 8.01 . The morphological and molecular characteristics of the reisolated root-knot nematode were identical to those of M. javanica. dai) J4 (female); (21 dai and 28 dai) female with gelatinous egg mass; (35 dai) egg-laying and the emergence of second-stage juveniles

M. javanica is confirmed as a pest of black pepper in Binh Phuoc Province and its management is suggested for sustainable production of black pepper in Vietnam.

Acknowledgments We thank Lai Thanh Giang, Nguyen Thi Ngoc Loan for technical assistance. We are grateful to Dr. Nguyen Bao Quoc (NLU, Vietnam) and Dr. Stéphane Bellafiore (IRD, France) for the helpful discussion and reviewing the manuscript before submission. This research is funded by the Vietnam National Foundation for Science and Technology Development (NAFOSTED) under grant number 106-NN.03-2015.86.

\section{References}

Bybd DW, Kirkpatrick T, Barker KR (1983) An improved technique for clearing and staining plant tissues for detection of nematodes. $\mathrm{J}$ Nematol 15(1):142-143

Eisenback JD (1985) Detailed morphology and anatomy of second-stage juveniles, males, and females of the genus Meloidogyne (root-knot nematodes) an advanced treatise on Meloidogyne, vol. 1. In: Sasser JN, Carter CC, editors. Raleigh, NC: North Carolina State University Graphics; pp. 47-78

Khương NB (1983) Plant parasitic nematodes of South Vietnam. J Nematol 15(2):319-323

Meng Q, Long H, Xu J (2004) PCR assays for rapid and sensitive identification of three major root-knot nematodes, Meloidogyne incognita, M. javanica and M. arenaria. Acta Phytopathol Sinica 34:204-210 
Nguyễn VP, Bellafiore S, Petitot AP, Haidar R, Bak A, Abed A, Gantet P, Mezzalira I, de Almeida EJ, Fernandez D (2014) Meloidogyne incognita - rice (Oryza sativa) interaction: a new model system to study plant-root-knot nematode interactions in monocotyledons. Rice 7:23. https://doi.org/10.1186/s12284-014-0023-4

Rammah A, Hirschmann H (1990) Morphological comparison of three host races of Meloidogyne javanica. J Nematol 22(1):56-68

Snyder DW, Opperman CH, Bird DM (2006) A method for generating Meloidogyne incognita males. J Nematol 38(2):192-194
Thuy TTT, Yen NT, Tuyet NTA, Te LL, De Waele D (2012) Plantparasitic nematodes and yellowing of leaves associated with black pepper plants in Vietnam. Arch. Phytopathol. Plant Prot. 45(10): 1183-1200. https://doi.org/10.1080/03235408.2012.659508

Zijlstra C, Donkers-Venne D, Fargette M (2002) Identification of Meloidogyne incognita, M. javanica and M. arenaria using sequence characterised amplified region (SCAR) based PCR assays. Nematology 2:847-853 